\title{
Progress in Identifying High Nature Value Montados: Impacts of Grazing on Hardwood Rangeland Biodiversity is
}

\author{
T. Pinto-Correia *, N. Guiomar, M.I. Ferraz-de-Oliveira, E. Sales-Baptista, J. Rabaça, C. Godinho, N. Ribeiro, \\ P. Sá Sousa, P. Santos, C. Santos-Silva, M.P. Simões ${ }^{1}$, A.D.F. Belo, L. Catarino, P. Costa, E. Fonseca, S. Godinho, \\ C. Azeda, M. Almeida, L. Gomes, J. Lopes de Castro, R. Louro, M. Silvestre, M. Vaz
}

ICAAM (Instituto de Ciências Agrárias e Ambientais Mediterrânicas Universidade de Évora), 7000 Évora, Portugal

\section{A R T I C L E I N F O}

\section{Article history:}

Received 9 March 2017

Received in revised form 16 January 2018

Accepted 19 January 2018

Available online xxxx

\section{Key Words:}

biodiversity

conservation policy

cork oak

ecosystem services

grazing

incentives

silvopastoral systems

\begin{abstract}
A B S T R A C T
Due to their complex structure and traditional low-intensity management, Portuguese oak woodland rangelands known as montados are often considered high nature value (HNV) farming systems, and as such, they may be deemed eligible for subsidies and incentives by governmental and nongovernmental agencies. Too little is known about how the HNV concept might be applied to conserve complex silvopastoral systems. These systems, due to their structural and functional complexity at multiple scales, tend to support high levels of biodiversity. Montados are in sharp decline as a result of the rapid specialization of land management that, through simplification, undermines multifunctionality. Understanding how changes in management influence these systems and their biodiversity is needed for prioritizing conservation efforts and for ensuring they remain HNV systems. On the basis of a field survey in 58 plots distributed among 29 paddocks on 17 farms, we conducted an integrated analysis of the relationship between grazing intensity and biodiversity in montados of similar biophysical and structural characteristics. Data on management were obtained through interviews, and biodiversity data (vegetation, macrofungi, birds, herpetofauna) were obtained through specific field protocols. Additional spatial data, such as soil characteristics, slope, land cover, and linear landscape elements, were also analyzed. The results show no overall biodiversity variation as a result of different management practices. However, different groups of species react differently to specific management practices, and within a pasture, grazing impacts are heterogenous. In low grazing intensity plots, macrofungi species richness was found to be higher, while bird species richness was lower. Using tree regeneration as proxy for montado sustainability, results show less tree regeneration in areas with higher forage quality and more intense grazing. Pathways for future progress are proposed, including creating areas within a paddock that attract grazing away from where regeneration is desired.
\end{abstract}

(c) 2018 The Society for Range Management. Published by Elsevier Inc. All rights reserved.

\section{Introduction}

Silvopastoral systems cover several million hectares of the European Union's (EU) agricultural land. They are mostly found in the southern EU countries, where there are environmental conditions that limit intensive and specialized farming, such as poor and shallow soils, steep slopes, and scarce water, characteristics common on Mediterranean rangelands (Rigueiro-Rodríguez et al., 2009; Bergmeier et al., 2010;

\footnotetext{
it This work was funded mainly by the project ALENT-07-0224-FEDER-001744. This work was also funded by national funds through the FCT - Foundation for Science and Technology under the Project UID/AGR/00115/2013.

* Correspondence: T. Pinto-Correia, ICAAM (Instituto de Ciências Agrárias e Ambientais Mediterrânicas Universidade de Évora), 7000 Évora, Portugal.

E-mail address: mtpc@uevora.pt (T. Pinto-Correia).

${ }^{1}$ Deceased.
}

Plieninger et al., 2015). These land use systems combine forestry and livestock production, in systems using extensive livestock grazing practices and supporting varying tree densities (McAdam et al., 2009; Bergmeier et al., 2010; Plieninger et al., 2011). Because their heterogeneity and multiple vegetation layers create a diverse mosaic of habitats and support high levels of biodiversity (Bugalho et al., 2011; Godinho et al., 2011), these silvopastoral systems are often pointed out as outstanding examples of HNV farmland in Europe (Cooper et al., 2007; Paracchini et al., 2008; Oppermann et al., 2012). The HNV concept (Beaufoy et al., 1994) was introduced to the research and policy spheres in the beginning of the 1990s as a way to acknowledge the role of specific farming systems in maintaining biodiversity and landscape quality in the European countryside (Peneva et al., 2015; Strohbach et al., 2015; EFNCP, 2017). This concept is based on the assumption that low-intensity agricultural management leads to smaller production outputs but results in higher biological and landscape diversity levels on farmland (Doxa et al., 2010; Lomba et al., 2015). As a policy designation, it 
makes the land eligible for a number of incentive and subsidy programs in European countries and from the EU.

The emergence of the HNV concept accompanies an increased demand for environmental sustainability and countryside conservation (Oppermann et al., 2012). The European Union's Biodiversity Strategy focuses on sites with existing conservation status including sites designated as within the EU's Natura 2000 program. Natura 2000 is an EUwide network of core breeding and resting sites for rare and threatened species, as well as for some rare natural habitat types (Baker, 2003; Jones-Walters and Čivić, 2013; Kati et al., 2015). This does not address many places with conservation value that are at higher risk of land use and management change because they do not have conservation status. The HNV concept addresses such places, as it expands efforts to encourage environmentally positive farming systems and maintain biodiversity beyond Natura 2000 sites and other lands in conservation status.

The Common Agricultural Policy of the European Union (CAP), particularly the production programs that are its first pillar, is the most powerful instrument influencing land use decisions at the farm level in Europe (Latruffe et al., 2013; Renwick et al., 2013; Ribeiro et al., 2014). Despite its strategic goals, which include the conservation of natural resources and biodiversity (van Zanten et al., 2014), the CAP has led to two opposing trends affecting the welfare of silvopastoral systems (Pinto-Correia and Azeda, 2017). The first scenario is abandonment of grazing, due to new and complex rules that limit participation of rangelands with trees and shrubs in subsidy programs, causing landowners to convert these areas to either forestry or crop production rather than maintaining an integrated system (Trisorio and Povellato, 2010). In the second scenario, grazing is intensified in response to subsidies offered on a per head basis, resulting in higher livestock stocking rates. In the long run, overstocking reduces the productivity of pastures and inhibits tree regeneration (Pinto-Correia et al., 2014; Almeida et al., 2016; Ferraz-de-Oliveira et al., 2016; Godinho et al., 2016b; Guerra et al., 2016; Pinto-Correia and Azeda, 2017). The HNV of silvopastoral systems is not secured under either of these outcomes. Characterizing the biodiversity values of silvopastoral systems under different management regimes is key to focusing conservation efforts and targeting environmental compensation payments or subsidies in ways that effectively conserve European wooded rangelands.

The Portuguese montado is the silvo-pastoral system dominant in Southern Portugal and one of the most characteristic in Europe (PintoCorreia et al., 2011b; Sá-Sousa, 2014). It covers approximately 1-m hectares and has a strong management tradition that integrates forestry and livestock production (Pinto-Correia and Godinho, 2013; Godinho et al., 2016b). The tree cover is composed of cork and holm oaks (Quercus suber and Quercus rotundifolia, respectively) at diverse densities (Godinho et al., 2016a), and the understory is either cultivated or in natural pasture, which may have shrubs, depending on management (Canteiro et al., 2011). Used for extensive livestock grazing, pastures may sometimes be cultivated to grow forage crops for supplementary animal feed. The low intensity of human use, together with different vegetation layers and the mosaic created by patches of differing tree and shrub densities, supports a diversified landscape and high levels of biodiversity (e.g., Martins-da-Silva et al., 2009; Bugalho et al., 2011; Godinho and Rabaça, 2011; Godinho et al., 2011; Almeida et al., 2013; Godinho et al., 2016a).

The montado is an outstanding illustration of the main challenges faced by silvopastoral landowners in the European context of changing and uncertain public policy interventions. Despite its conservation value, both market mechanisms and public policies (Almeida et al., 2013; Pinto-Correia and Azeda, 2017) create pressures for simplification of the system through specialization and intensification. The intensification of grazing explains ongoing changes in livestock grazing: replacement of sheep and Iberian pigs by cattle, replacement of indigenous cattle breeds by imported and heavier breeds, and higher stocking densities. These changes lead to soil compaction, increased fodder needs, and much stronger pressure on pastures and tree regeneration. With higher grazing pressure there are also fewer shrub patches. With less natural tree regeneration, tree cover tends to decline in density over time. The structural diversity of the montado is reduced, as well as its biodiversity value (Almeida et al., 2016; Pinto-Correia and Azeda, 2017). These trends mean that not all montados can still be considered HNV. But if those montados with HNV could be clearly identified, it would be possible to target public policies so that they would receive support for maintaining their conservation values.

The aim of this paper is to bring new insights into the assessment of the impact of management practices, particularly livestock grazing, on two aspects of montados that are important to maintaining a montado's classification as HNV: 1) biodiversity as represented by selected species groups and 2) tree regeneration and recruitment, as tree recruitment is crucial for a montado's structural diversity and a proxy for its stability.

We have applied an analytical approach integrating a set of different indicators of montado vegetation structure and biodiversity values and assessed how they are connected to management practices. Such an approach required disciplinary integration, both in the sampling design and for data collection protocols, as well as in the analysis. Social science and spatial analysis were particularly relevant to defining the sampling approach and integrating input from the different disciplines involved; social scientists designed the interview guide after consulting agronomy, forestry, and conservation specialists; the specialists for each taxonomic group were obliged to collaborate on the sampling strategy for each selected property so that data could later be analyzed jointly. The results are expected to bring useful insights informing the design of future policy tools for the montado.

\section{Material and Methods}

\section{Study Area and Sampling Design}

The study was conducted in the European Natura 2000 network site of Monfurado (PTCON0031), mainly located in the municipality of Montemor-o-Novo and partly in the municipality of Évora (Fig. 1), in southern Portugal. The site has $\sim 24000$ ha, and the maximum elevation within the study area is $424 \mathrm{~m}$ above sea level. About $71.07 \%$ of this site is covered by well-preserved montados dominated by cork and holm oaks with a wide range of tree densities. This spatial fuzziness is a core characteristic of these silvopastoral land use systems (Pinto-Correia et al., 2011a; Godinho et al., 2016a), along with an understory mosaic of natural pastures, cereal and forage crops, and shrubs. In our study area, the management of the montado is mainly focused on livestock production, combined with the forest products of cork and wood for charcoal production.

In order to better assess management activities and variations, the study was focused on private montado properties managed for livestock production in combination with cork. Real-world situations are difficult to compare in detail due to their diverse characteristics. To minimize the variability associated with montado sample areas, the areas selected for sample plots were characterized by the following: a relatively dense tree canopy of $30-50 \%$ cover, dominance by cork oaks, similar soils with no registered limitations for grazing and forestry, and gentle slopes ( $0-15 \%$ slope).

We selected 58 sampling sites. One high-intensity and one low-intensity grazing plot of 1.5 ha were designated in each of 29 paddocks (average size: 42.93 ha; minimum size: 10.56 ha; maximum size: 97.35 ha). Paddocks were mainly grazed by cattle (12 parcels; mean stocking density $=0.629 \mathrm{LU} / \mathrm{ha} / \mathrm{yr}$ ) or jointly by cattle and sheep ( 9 parcels; mean stocking density $=0.667 \mathrm{LU} / \mathrm{ha} / \mathrm{yr}$ ). The remaining paddocks are grazed by cattle and pigs together ( 5 parcels; mean stocking density $=0.271 \mathrm{LU} / \mathrm{ha} / \mathrm{yr}$ ), pigs only (2 parcels; mean stocking density $=0.024 \mathrm{LU} / \mathrm{ha} / \mathrm{yr}$ ); and sheep only ( 1 parcel; stocking density $=0.292$ $\mathrm{LU} / \mathrm{ha} / \mathrm{yr}$ ) 